\title{
TUGAS 2 - Audit Sistem Informasi
}

\section{ANALISA RESIKO AUDIT SISTEM INFORMASI \\ HARUM TRI LESTARI \\ 165100110}

Fakultas Komputer

Harumtrilestari.student@ umitra.ac.id

\begin{abstract}
Salah satu tahap audit ialah perencanaan (audit planning). Tujuan audit planning ialah untuk menentukan pada area mana, bagaimana, kapan serta oleh siapa (anggota tim yang mana) audit akan dilakukan. Langkah penting dalam audit planning mengidentifikasikan faktor risiko. Auditor harus menilai faktor risiko intern, misalnya sistem online, network, database, dan teknologi canggih lainnya memiliki risiko lebih besar daripada batch processing system (apalagi dibandingkan sistem manual).
\end{abstract}

A. PENDAHULUAN

Auditor harus menilai faktor risiko intern, misalnya sistem online, network, database, dan teknologi canggih lainnya memiliki risiko lebih besar daripada batch processing system (apalagi dibandingkan sistem manual).

\section{B. PEMBAHASAN / STUDI KASUS menganalisa resiko}

Tujuan analisis resiko ini untuk membantu auditor agar lebih fokus audit pada area yang faktor risikonya besar. Untuk itu auditor menyiapkan rencana kerja audit (audit program) mengenai batas, jadwal, dan prosedur untuk mencapai sasaran audit

contoh :

\section{PengamananAset}

Aset informasi suatu perusahaan seperti perangkat keras (hardware), perangkat lunak (software), sumber daya manusia, file data harus dijaga oleh suatu sistem pengendalian intern yang baik agar tidak terjadi penyalah gunaan aset perusahaan 


\section{Menjaga integritas data}

Data memeiliki atributatribut tertentu seperti: kelengkapan, keberanaran, dan keakuratan. Jika integritas data tidak terpalihara, maka suatu perusahaan tidak akan lagi memilki hasil atau laporan yang beanr bahkan perusahaan dapat menderita kerugian

\section{ID SECURITY}

QWTD4452377-ASP-5244107

\section{KESIMPULAN}

Apabila perusahan terdapat musibah yang mengakibatkan krisis financial atau krisis yang lainya yang mengakibatkan kebangkrutan peruhaan harus merubah sistem pengendalian agar tetap financial perusahaan stabil.

\section{E. DISKUSI}

Saya bersama teman saya bernama Wita mendiskusikan tentang analisa resiko audit sistem informasi dengan sangat baik , hasil diskusi dari materi ini adalah auditor harus menilai setiap kekuatan pengendalian internal sehingga resiko pengendalian dapat di perikirakan.dan cara ,mengurangi resiko adalah pengurangan karyawan dan pengurangan jumlah produksi yang dihasilkan 


\section{F. REFERENCE}

[1] O. M. Febriani and A. S. Putra, "Sistem Informasi Monitoring Inventori Barang Pada Balai Riset Standardisasi Ind ustri Bandar Lampung," J. Inform., vol. 13, no. 1, pp.90-98, 2014.

[2] A. S. Putra, "Paperplain: Execution Fundamental Create Application With Borland Delphi 7.0 University Of Mitra Indonesia," 2018.

[3] A. S. Putra, "2018 Artikel Struktur Data, Audit Dan Jaringan Komputer," 2018.

[4] A. S. Putra, "ALIAS MANAGER USED IN DATABASE DESKTOP STUDI CASE DB DEMOS." A. S. Putra, "COMPREHENSIVE SET OF PROFESSIONAL FOR DIS TRIBUTE COMPUTING."

[6] A. S. Putra, "DATA ORIENTED RECOGNITION IN BORLAND DELPHI 7.0."

[7] A. S. Putra, "EMBARCADERO DELPHI XE 2 IN GPUPOWERED FIREMONKEY APPLICATION."

[8] A. S. Putra, "HAK ATAS
KEKAYAAN INTELEKTUAL DALAM DUNIA TEKNOLOGY BERBASIS REVOLUSI INDUSTRI 4.0."

[9] A. S. Putra, "IMPLEMENTASI PERATURAN PERUNDANGAN UU. NO 31 TAHUN 2000 TENTANG DES AIN INDUSTRI BERBASIS INFORMATION TECHNOLOGY."

[10] A. S. Putra, "IMPLEMENTATION OF PARADOX DBASE."

[11] A. S. Putra, "IMPLEMENTATION OF TRADE SECRET CASE STUDY SAMSUNG MOBILE PHONE."

[12] A. S. Putra, "IMPLEMENTATION PATENT FOR APPLICATION WEB BASED CASE STUDI WWW. PUBLIKLAMPUNG. COM."

[13] A. S. Putra, "IMPLEMENTATION SYSTEM FIRST TO INVENT IN DIGITALLY INDUSTRY."

[14] A. S. Putra, "MANUAL REPORT \& INTEGRATED DEVELOPMENT

ENVIRONMENT BORLAND DELPHI 7.0."

[15] A. S. Putra, "PATENT AS RELEVAN SUPPORT RESEARCH."

[16] A. S. Putra, "PATENT FOR RESEARCH STUDY CASE OF APPLE. Inc."

[17] A. S. Putra, "PATENT PROTECTION FOR APPLIC ATION INVENT."

[18] A. S. Putra, "QUICK REPORT IN

PROPERTY 
PROGRAMMING."

A. S. Putra, "REVIEW
CIRCUIT COMPONENT

REQUIREMENT ON ASUS NOTEBOOK."

[20] A. S. Putra, "REVIEW

TRADEMARK PATENT FOR INDUSTRIAL TECHNOLOGY BASED 4.0."

[21] A. S. Putra, "TOOLBAR COMPONENT PALLETTE IN OBJECT ORIENTED PROGRAMMING."

[22] A. S. Putra, "WORKING DIRECTORY SET FOR PARADOX 7."

[23] A. S. Putra, "ZQUERY CONNECTION IMPLEMENTED

PROGRAMMING STUDI CASE PT. BANK BCA Tbk."

[24] A. S. Putra, D. R. Aryanti, and I. Hartati, "Metode SAW (Simple Additive Weighting) sebagai Sistem Pendukung Keputusan Guru Berprestasi (Studi Kasus: SMK Global Surya)," in Prosiding Seminar Nasional Darmajaya, 2018, vol. 1, no. 1, pp. 85-97.

[25] A. S. Putra and O. M. Febriani, 'Knowledge Management Online Application in PDAM Lampung Province," in Prosiding International conference on Information Technology and Business (ICITB), 2018, pp. 181-187.

[26] A. S. Putra, O. M. Febriani, and B. Bachry, 'Implementasi Genetic Fuzzy System Untuk Mengidentifikasi Hasil Curian Kendaraan Bermotor Di Polda Lampung," SIMADA (Jurnal
Sist. Inf. dan Manaj. Basis Data), vol. 1, no. 1, pp. 21-30, 2018.

[27] A. S. Putra, H. Sukri, and K. Zuhri, "Sistem Monitoring Realtime Jaringan Irigasi Desa (JIDES) Dengan Konsep Jaringan Sensor Nirkabel," IJEIS (Indonesian J. Electron. Instrum. Syst., vol. 8, no. 2, pp. 221-232.

[28] D. P. Sari, O. M. Febriani, and A. S. Putra, "Perancangan Sistem Informasi SDM Berprestasi pada SD Global Surya," in Prosiding Seminar Nasional Darmajaya, 2018, vol. 1, no. 1, pp. 289-294. 